\title{
Direction of Entrepreneurial Ecosystem
}

\author{
Basavaraj G.N
}

\begin{abstract}
Despite a turbulent year for many, the top five global startup ecosystems maintain their reign at the top, with Silicon Valley in the \#1 position, followed by New York City and London tied for \#2 for the second year in a row. Beijing and Boston follow at \#4 and \#5, respectively. North America continues to dominate the Global Rankings, with $50 \%$ of the Top 30 ecosystems coming from this region, followed by Asia with $27 \%$ and Europe with $17 \%$ of the top performing ecosystems globally. The global startup economy is worth over \$3.8 trillion in Ecosystem Value, more than the individual GDP of most G7 economies, not including the value of exits prior to 2018. There are now 79 ecosystems generating over \$4 billion in value which is more than double the number identified in 2017.91 ecosystems created unicorns in 2020.
\end{abstract}

Keywords: Start Up Ecosystem Start Up Growth Mangement in Start Up, Growth Economy, Start Up Worldwide

The $\$ 3$ trillion global start-up economy ... where and how start-up ecosystems are driving new growth.

The global startup economy is worth nearly $\$ 3$ trillion, a rise of $20 \%$ in two years. That's the size of a not-so-small economy, larger than the GDP of the UK, France, or Brazil. Technology-driven startups aren't just contributing to economic growth, in many ways, they are economic growth.

The 2019 Global Startup Ecosystem Report (GSER) has just been published by Startup Genome in partnership with the Global Entrepreneurship Network. It is the world's most comprehensive and widely-read research on startups.

The report ranks the top 30 startup ecosystems around the world.

- The top 5 are: Silicon Valley, New York City, London, Beijing, and Boston.

- Paris cracked the top 10, moving up two spots from 2017 to \#9 overall.

- TNW's host ecosystem, Amsterdam-StartupDelta, had the biggest jump in the top 30, climbing four spots to \#15 globally.

- 9 European startup ecosystems are ranked in the top 30: London, Paris, Berlin, Stockholm, AmsterdamStartupDelta, Lausanne-Bern-Geneva, Munich, and Barcelona.

The report explores how startups are revitalising traditional industry sectors through the application of technology. Based on the data, investors should look into the following sectors:

- The fastest-growing Startup Sub-Sectors in terms of funding, exits, and startup creation are: Advanced
Manufacturing \& Robotics, Blockchain, Agtech\& New Food, and Artificial Intelligence.

- Meanwhile, some sub-sectors have seen falling levels of investment and startup creation, including Edtech, Digital Media, Gaming, and Adtech.

Whilst many of the top locations are familiar to us, there is also tremendous growth taking place everywhere.

a) Across the world, there are 25 startup ecosystems with an Ecosystem Value above $\$ 10$ billion each, adding up to nearly $\$ 1$ trillion in economic value.

b) Additionally, 57 startup ecosystems boast an Ecosystem Value between $\$ 1$ billion and $\$ 10$ billion, creating thousands of jobs and billions in economic productivity.

c) In fast-growing sub-sectors like AI and Block chain, small but vibrant ecosystems are rapidly emerging as hotspots:

- In AI, ecosystems to watch include Edmonton, Houston, Greater Helsinki, and Taipei City.

- In Blockchain, up-and-comers include Belgrade and Novi Sad (Serbia) and Vancouver.

d) Miami, long known for a vibrant entrepreneurship scene, broke into the top 30 overall ranking for the first time.

\section{Ecosystems}

Forbes recently said "Startup ecosystems are popping up all across the country and the world, with varying levels of success. I wanted to talk about the mix of ingredients that are needed to make a startup ecosystem thrive over time. So, leaders in your local communities can have a blueprint with which to follow to propel your startup ecosystem, and hopefully, your own success in the process."

Here, as an example, is a visualisation of the start-up ecosystem in Sacremento: 


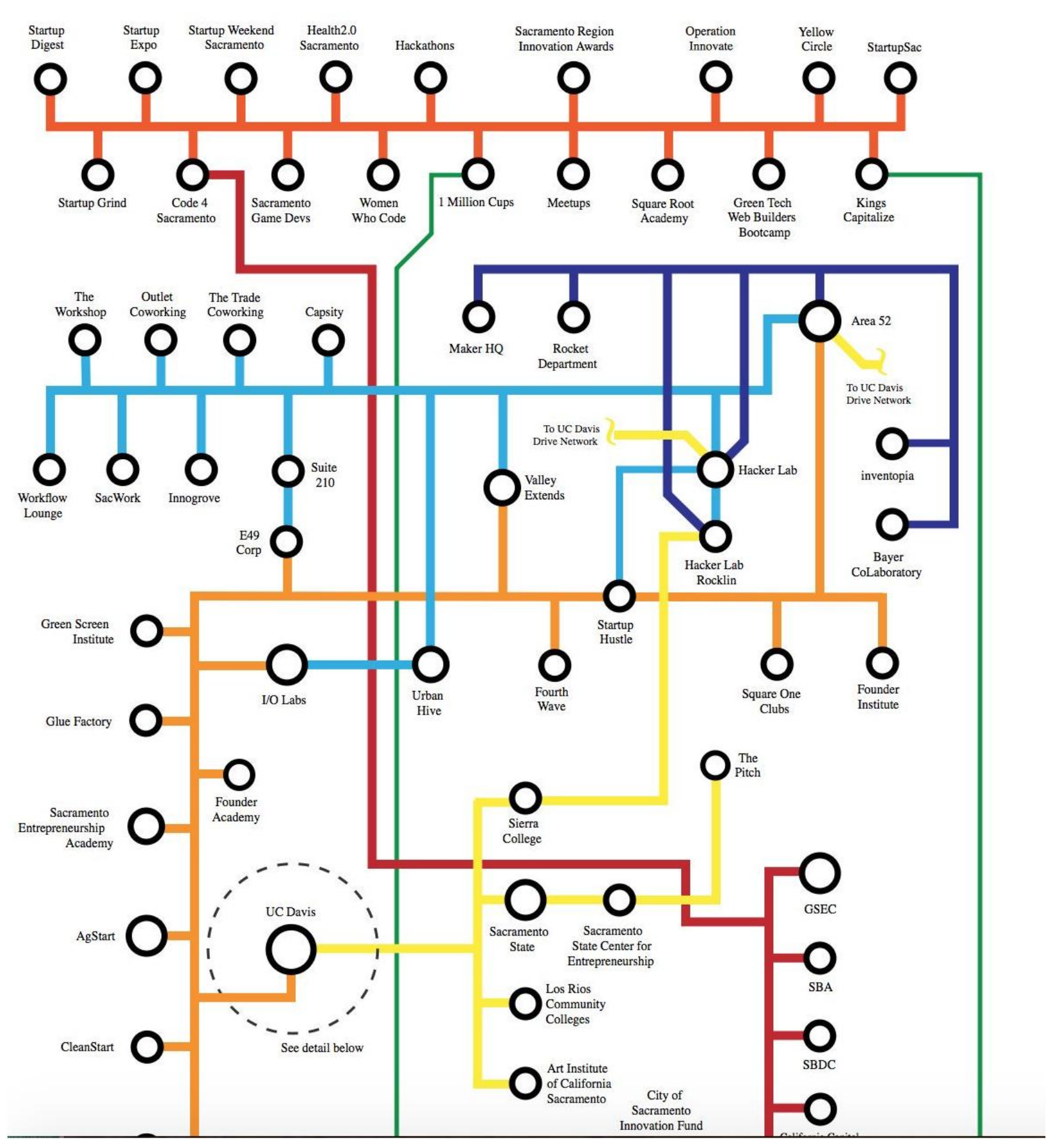

The Most Important Ingredients

- Access to Great Ideas. Great ideas turn into great businesses. Think building "platforms" over "features", or "wisdom" over "widgets", or "painkillers" over "vitamins". Startups are hard in all cases, might as well be working on really big ideas.

- Access to Talent. Great entrepreneurs, preferably serial entrepreneurs that have learned from prior mistakes, are ultimately going to dictate the success of their businesses, and in turn, the success of the ecosystem.

- Access to Capital. The best ideas and the best talent are useless without the capital to fund their vision. If that capital is local, great, as investors like to invest close to home. If that capital is located in another city, that is also great, provided investors in those towns are willing to deal with travel (which they often don't). It is critical that the capital is available to embrace each stage of development, from seed to early to growth stages of your business. Having seed stage, but not Series A or Series B stage is a recipe for a likely "flame-out" of that startup, when they hit the wall in that level of their growth.

- Access to Customers. To me, this is the most important piece. Customers drive revenues. Revenues impress investors. Investors fund growth. Growth leads to big exits. Big exits leads to a robust ecosystem. This often means tight partnerships between early stage ideas with later stage companies to buy those services (ones who are supportive to helping the local startup community)

\section{The Key Players}

- Entrepreneurs: Duh, you need experienced teams running the startup businesses. With an equal balance of needed skillsets from strategy, to marketing, to technology, etc. 
- Mentors: First time entrepreneurs need to be able to ask questions of experienced leaders, to help get them up the learning curve, without making the same mistakes of their predecessors.

- Investors: Whether these are individual angels, organized angel networks, venture capital firms, private equity firms, family offices, corporations or other funding sources doesn't matter. What matters is the money is flowing from whoever can cut the checks for that stage of a business's growth.

- Incubators: This category picks up everything from shared office spaces for startups, all the way up to formal startup accelerator programs with formal educational curriculum. The point is, entrepreneurs can learn from each other, when they are in close proximity to each other.

- Universities: A lot of the biggest business ideas are born from the research inside of universities. Having a healthy technology transfer process for these ideas to be monetized by business leaders is key. And, university professors need to know, it is perfectly acceptable to try and monetize their ideas, at the same time they are trying to win a Nobel prize (which many don't agree with).

- Corporations: The big companies in town help in many ways. They invest through corporate venture capital funds. They become potential customers of new local startups. They have pain points of their own, that a local startup can build and solve for them. They are often the exit for startups that have gotten large in size. You need a really healthy interaction between the startups and corporations working towards a common goal.

- Associations/Events: There are many groups in town that help organize and propel the ecosystem. This could be industry trade associations, venture capital associations, entrepreneur networking groups, chambers of commerce, economic development groups, etc. Leverage these groups of like-minded people at their big annual events or leverage their tools (e. g., job boards on their websites).

- Government: Whether it is at the city, county or state level, your local government can play a very important role. That could include providing tax incentives for startups to launch in their city, tax free profits on any capital gains in a startup (to help stimulate investment), passing ecosystem friendly laws (like free access to the internet), or establishing venture capital funds with a portion of their treasury.

- Service Providers: The lawyers, accountants, bankers, recruiters, agencies, advisors, and consultants in your community all play a role. The more experienced they are with startups, the better advice they will bring to the ecosystem.

Here is an example of the collective start-up ecosystem in the Netherlands:

\section{Optimal Ownership \& Economics}

- Spread Equity Deep: Most entrepreneurs concentrate equity into only a couple people at the top of the organization. It is better to spread equity deep into other employees, as well. Why? Because if employees have a vested interest in the business, they will work harder towards hitting the goal. And, when the company sells for $\$ 1 \mathrm{BN}$, it creates hundreds of multi-millions that have new-found funds to start their next startup, powering the ecosystem to the next level.

- Serial Exits: Selling companies for big returns impress investors. But, often times a first time entrepreneur, will see a \$50MM sale as "big money", and sell too early to put some cash in the bank for a rainy day. But, a second or third time entrepreneur has already banked cash from their first exit, and now they are in a position to "roll the dice", walking from a $\$ 50 \mathrm{MM}$ sale, in hopes of a $\$ 500 \mathrm{MM}$ sale down the road.

- Reinvest Returns: Money that simply goes into the bank account, or into safe real estate investments, does not help the ecosystem. The money needs to round trip back into the community. So, if you sell for $\$ 100 \mathrm{MM}$, hopefully a good chunk of that is funding other startups in the ecosystem.

- Shoot for the Moon: Many investors are simply too conservative for a startup ecosystem to be successful. Silicon Valley prides itself on "failure as a badge of honor", as the lessons learned in one bad startup, will apply to the next good startup. If you are too conservative, trying to cross potential "strikeouts" off your list, you are most likely crossing off potential "home runs" at the same time.

\section{In General}

- It Takes Leadership: It takes a couple cheerleaders at the top that are going to "plant the flag" and have everyone rally around those goals for the community. Preferably, somebody that can put their money where their mouth is, and can lean on their deep rolodex of key relationships in your region (e. g., the governor, the mayor, the local billionaires).

- Leverage Local Strengths: Figure out what your region does better than others, and focus your efforts around those industries or skills. For example, New York would be a great place for financial startups and Los Angeles would be a great place for entertainment related startups, given the high concentration of experts in those areas.

- It Requires Startup Density: It will be really hard to build a robust community in very small towns. There simply isn't enough activity, breadth of industries or depth of expertise in any one industry to be effective. So, either live in a town big enough to support an ecosystem, or prepare for a lot of travel between a bunch of smaller regions that have been aggregated into one community.

- Collaborate Across Regions: Don't think a startup ecosystem is isolated to your city. The best startup ecosystems feed off each other. Think about the collaboration happening between New York and Boston startups, given their close proximity to each. Or, between Detroit and Germany, because they both serve the auto industry, as examples.

- Publicity Helps: The rest of the country needs to know what you are up to. Less about your desire to build an ecosystem. But more about the venture capital flowing into your region, or big exits being realized at big valuations. So, celebrate your successes, and put those 
success stories locally "on display", or nationally "on the road". That will get investors and talent to want to check it out.

- Progress Must Be Measured: Like with any business endeavor, you must have good measurement with which to manage it. Quantify key metrics like the amount capital raised, investor value created, companies formed, jobs created and material exits in your market, and shoot to have those metrics improve year over year.

- It Can't Be Forced: The community needs to share a common goal. The goal of building a robust community can't simply be embraced by a few, to be forced on others; it has to be embraced by everybody participating in the community, for it to be successful.

- It Takes Time: Don't expect miracles overnight. Ecosystems are not built in years, they are built over decades. That is why Silicon Valley's startup ecosystem is as big as it is; they have literally been working on it since the 1970's, a fine tuned machine after 40 years of optimization.

\section{Superclusters}

However start-up ecosystems should not just be about supporting local start-ups.

Christian Rangen is a leading thinker in developing "innovation superclusters". He says "As we continue to race into the knowledge-driven economy, with industry 4.0, digital business models, lean startups, large-scale industry shifts; local and national leaders take note."

"How can we compete globally?", "How do we create more high-impact, tech jobs?", "How do we create - and keep tech scale-ups in our local economies?" are frequent questions discussed at roundtables and conferences.

The best leaders shift that conversation. Instead, they ask and act on strategic questions like, "How can we attract the very best startups and scale-ups to our region?", "how can we combine our old legacy industries, with new technologies at scale", "how can we enable and support unprecedented collaboration at scale?" and "how can we accelerate innovation across research, corporate, startup and beyond? 